\title{
Comparação entre onset e coda silábica durante a aquisição fonológica
}

\author{
Comparison between syllabic onset and coda during \\ phonological acquisition
}

\author{
Daniela Evaristo dos Santos Galea ${ }^{1}$, Haydée Fiszbein Wertzner ${ }^{2}$
}

\begin{abstract}
RESUMO
Objetivo: Verificar se há diferença entre a porcentagem de acertos em onset e coda de sílaba dos fonemas /s/ e /r/ em crianças de 2:1 a 3:0 anos de idade. Métodos: Participaram da pesquisa 88 crianças em desenvolvimento fonológico típico: GI: 41 crianças de 2:1 a 2:6 anos e GII: 47 crianças de 2:7 a 3:0 anos. Todas frequentavam creche pública e não apresentavam queixa de problema de linguagem, mais de três ocorrências de otite média e nem eram bilíngues. A coleta de dados foi realizada por três provas de fonologia: nomeação, imitação e fala espontânea. Resultados: Quanto à comparação do /s/, houve diferença apenas no GII na prova de nomeação em sílaba final ( $\mathrm{p}=0,038$ ), com melhor desempenho em coda que em onset. Embora não tenha havido diferença estatística nas demais provas e sílabas analisadas, as crianças dos dois grupos apresentaram melhor desempenho em onset que em coda, com exceção das crianças do GI na imitação em sílaba final e na nomeação em sílaba inicial. Em relação ao /r/, em todas as comparações de sílaba final as crianças dos dois grupos tiveram média estatisticamente maior em onset que em coda. Na sílaba medial, as crianças tiveram melhor desempenho em onset, porém, não houve diferença significante ( $\mathrm{p}=0,205)$. Conclusão: de forma geral, notou-se que não houve diferença entre o/s/ em onset e coda silábica. Porém, quanto ao /r/, houve diferença entre as duas posições na sílaba, sendo que em onset as crianças dos dois grupos tiveram mais acertos.
\end{abstract}

Descritores: Linguagem infantil; Desenvolvimento infantil; Desenvolvimento da linguagem; Testes de articulação da fala; Medida da produção da fala; Fonética

\section{INTRODUÇÃO}

No Português Brasileiro, 16 consoantes podem ocupar a posição de onset silábico, ou seja, no início da sílaba no início da palavra e, 19 em onset silábico dentro da palavra. Em coda silábica, isto é, no final da sílaba, apenas as consoantes /S/, /R/, /l/ e /N/ ocupam esta posição. Mesmo assim, há algumas restrições para estas consoantes.

$\mathrm{O} / \mathrm{l} / \mathrm{em}$ final de sílaba tende a uma vocalização, levando-o ao /u/, como na oposição entre "mal" e "mau", tornando-os homônimos ${ }^{(1-2)}$. Este fato ocorre na maioria das regiões brasilei-

Trabalho realizado no Departamento de Fisioterapia, Fonoaudiologia e Terapia Ocupacional da Faculdade de Medicina da Universidade de São Paulo - USP - São Paulo (SP), Brasil.

(1) Doutora, Colaboradora do Laboratório de Investigação Fonoaudiológica em Fonologia do Departamento de Fisioterapia, Fonoaudiologia e Terapia Ocupacional da Faculdade de Medicina da Universidade de São Paulo - USP - São Paulo (SP), Brasil.

(2) Livre-Docente, Professora Associada do Departamento de Fisioterapia, Fonoaudiologia e Terapia Ocupacional da Faculdade de Medicina da Universidade de São Paulo - USP - São Paulo (SP), Brasil.

Endereço para correspondência: Daniela Evaristo dos Santos Galea. Av. Barão de Campos Gerais, 116/32, Real Parque, São Paulo (SP), Brasil, CEP: 05684-000. E-mail: danielagalea@uol.com.br

Recebido em: 6/2/2009; Aceito em: 6/8/2009 ras. Porém, no sul do Brasil, o /l/ é considerado como consoante final, pois se observa a interrupção do fluxo do ar na cavidade oral pelo levantamento da ponta da língua junto aos dentes.

No que se refere à consoante final $/ \mathrm{N} /$, pode-se considerar que haja nasalização da vogal anterior, gerando 12 vogais possíveis no português, sendo sete orais e cinco nasais ${ }^{(2)}$ ou, que as vogais nasais do português consistem na junção de uma vogal oral com o arquifonema /N/. Assim, apenas de sete vogais é constituído o sistema fonético do português ${ }^{(1)}$.

Durante a aquisição fonológica, as crianças cometem alguns erros envolvendo os fonemas. À medida que a idade aumenta, os erros diminuem e as crianças produzem os fonemas mais corretamente $\mathrm{e}^{(3-5)}$.

Alguns estudos que serão expostos a seguir mostram a idade de aquisição de determinados fonemas bem como os erros que as crianças cometem durante este percurso.

Em relação ao /s/ em início de sílaba, uma pesquisa com crianças em desenvolvimento fonológico típico de 3:0 a 4:0 anos mostrou que ele já se encontra adquirido embora as crianças ainda realizem omissão e substituição ${ }^{(6)}$. Outro estudo mostra que este fonema é adquirido aos 2:6 anos de idade e que a substituição mais comum do $/ \mathrm{s} /$ é por $/ \int^{/(7)}$. O mesmo fonema em posição de coda silábica é adquirido anteriormente aos 
três anos de idade em estudo da região de São Paulo ${ }^{(8)}$ e aos 2:6 em posição final de palavra e aos 3:0 em coda silábica dentro da palavra no sul do Brasil ${ }^{(9)}$. Além disso, durante a aquisição em posição de final de palavra, a palatalização e a epêntese são mais observadas que as omissões. Ao contrário, no meio da palavra, observam-se mais omissões ${ }^{(9)}$.

A líquida /r/ em onset silábico é adquirida aos 4:2 anos ${ }^{(10)}$ em estudo da região sul do Brasil. Um deles ainda mostra que as substituições por /l/ e as semivocalizações são os erros mais observados durante este percurso. Outro estudo com crianças de 2:6 a 5:0, ao revisar pesquisas anteriores, mostra que quando as crianças apresentam dificuldade na aquisição deste fonema, elas o substituem por ///, /y/, /w/, /R/ ou o omitem ${ }^{(11)}$.

Na posição de final de sílaba, coda silábica, o arquifonema /R/ é adquirido aos 4:6 anos em sílaba final e, aos 6:0 anos em sílaba inicial ${ }^{(8)}$. Outra pesquisa mostra que a aquisição ocorre tanto em posição medial como final de palavra aos 3:10 anos de idade. As omissões do /R/ são mais observadas em posição medial e as semivocalizações e as substituições por líquidas laterais em posição final de palavra ${ }^{(9)}$.

Uma pesquisa com crianças de 1:0 a 7:1 anos de idade durante a aquisição fonológica do português observou que há omissão do arquifonema antes da aquisição correta da sílaba CVC ou VC. Foi realizada análise acústica da vogal precedente, mostrando que ela era mais alongada. Este fato indica que as crianças possuem conhecimento a respeito da existência da coda antes de a produzirem ${ }^{(12)}$.

As crianças de 2:1 a 3:0 anos falantes do português da região de São Paulo ainda comentem erros na estrutura CVC, marcados pela omissão da consoante final ${ }^{(13)}$. A simplificação da consoante final é observada em vários estudos da aquisição do português do Brasil ${ }^{(3,14-15)}$.

Outro erro comumente observado em relação às fricativas e líquidas é a distorção ${ }^{(8,16-17)}$. Alguns autores apontam que elas ocorrem devido à imaturidade do sistema neuromotor ${ }^{(18-19)}$. Observa-se, no entanto, que, à medida que as crianças ficam mais velhas, estas distorções diminuem ${ }^{(16-17,20-21)}$.

A partir das pesquisas acima mencionadas, a hipótese do presente estudo é de que há diferença no acerto do fonema /s/ em posição de onset e coda silábica. Ao contrário, não haveria diferença entre o/f/ em onset e coda de sílaba.

Assim, o objetivo da presente pesquisa foi verificar se há diferença entre a porcentagem de acertos em onset e coda de sílaba dos fonemas /s/e / / / em crianças de 2:1 a 3:0 anos de idade, nas provas aplicadas.

\section{MÉTODOS}

\section{Participantes}

Participaram da pesquisa 88 crianças em desenvolvimento fonológico típico, divididas em dois grupos: GI - 41 crianças de 2:1 a 2:6 anos de idade (23 meninas e 18 meninos) e GII - 47 crianças de 2:7 a 3:0 anos de idade (24 meninas e 23 meninos).

Como critérios de inclusão, as crianças não poderiam apresentar, segundo relato dos responsáveis na anamnese realizada, queixas de problema de linguagem ou audição, três ou mais ocorrências de otite média e bilinguismo. Além disso, para serem incluídas na pesquisa deveriam ter desempenho adequado na prova de vocabulário do ABFW - Teste de Linguagem Infantil nas áreas de fonologia, semântica, fluência e pragmática ${ }^{(22)}$, já que um desempenho alterado neste teste poderia indicar alguma alteração de linguagem.

Todas as crianças frequentavam creches conveniadas à Prefeitura do Município de São Paulo. No total, foram visitadas seis creches para que todas as crianças pudessem ser avaliadas no período de oito meses.

\section{Procedimento}

Esta pesquisa foi aprovada pela Comissão de Ética da Faculdade de Medicina da Universidade de São Paulo (FMUSP), no 358/01, em 9 de agosto de 2001.

Primeiramente, os responsáveis pelas crianças foram convocados a responderem à anamnese e a preencherem o Termo de Consentimento Livre e Esclarecido, permitindo a participação das crianças na pesquisa.

Posteriormente, foi aplicada a prova de vocabulário do $\mathrm{ABFW}^{(22)}$ e aquelas crianças que tiveram resposta adequada para a idade, de acordo com o padrão do teste, entraram na pesquisa.

Foram aplicadas três provas de fonologia: nomeação, imitação e fala espontânea.

As provas de imitação e nomeação aplicadas foram as do $\mathrm{ABFW}^{(23)}$ e, na prova de fala espontânea, a primeira autora interagia com a criança durante 15 minutos em situação de brincadeira, com miniaturas de objetos, a fim de coletar $15 \mathrm{mi}-$ nutos de amostra de fala ${ }^{(24)}$. Nesta prova apenas os substantivos dos dez minutos intermediários de gravação foram analisados.

Na prova de nomeação, foram utilizados objetos ao invés de figuras. Quando a criança não sabia, o nome do objeto era falado pela avaliadora e, após apresentação de cinco outros objetos, retornava-se a ele para a criança nomeá-lo. Caso, mais uma vez ela não soubesse o nome, este era descartado da análise.

Na prova de imitação do mesmo teste, quando a criança deixava de imitar algum vocábulo, este era novamente apresentado ao final da prova.

Como não havia um tempo determinado para aplicação das provas de nomeação e imitação, tomava-se como término da avaliação a completa realização desta prova pelas crianças. No entanto, a prova de fala espontânea durava 15 minutos.

Anteriormente à transcrição de todos os dados da pesquisa, foi realizado um pareamento da transcrição entre a primeira autora e um juiz fonoaudiólogo, cursando a pós graduação. $\mathrm{O}$ pareamento mostrou $85,71 \%$ de acordo na nomeação e $87,5 \%$ na imitação. Assim, após correções destas transcrições, os demais dados puderam ser transcritos para haver maior fidedignidade das análises.

Os fonemas /s/ e /r/ foram observados em posição inicial de sílaba (onset silábico) como em "śapo" ou tesoura" e em posição final de sílaba (coda silábica) como em "pașta" ou "tambor". Estes fonemas foram observados nas silabas inicial (somente o/s/, já que o/r/ não ocupa esta posição no Português do Brasil), medial e final de palavra.

Como o estudo aqui proposto foi realizado na região de São Paulo, supôs-se que haveria vocalização do /1/. Desta forma, 
Tabela 1. Comparação entre /s/ em onset e coda de sílaba na provas de fonologia

\begin{tabular}{|c|c|c|c|c|c|}
\hline Grupo & Prova & Sílaba & Média - coda & Média - onset & Valor de $\mathrm{p}^{\star \star}$ \\
\hline \multirow[t]{4}{*}{ GI } & Fala espontânea & inicial & 27,50 & 63,64 & 0,082 \\
\hline & Imitação & inicial & 10,00 & 24,39 & 0,067 \\
\hline & & final & 42,50 & 41,67 & 0,933 \\
\hline & Nomeação & inicial & 22,73 & 21,54 & 0,909 \\
\hline \multirow[t]{5}{*}{ GII } & Fala espontânea & inicial & 48,40 & 62,50 & 0,312 \\
\hline & & final & 70,00 & 77,65 & 0,618 \\
\hline & Imitação & inicial & 39,13 & 48,94 & 0,299 \\
\hline & & final & 70,21 & 51,06 & $0,038^{*}$ \\
\hline & Nomeação & inicial & 44,87 & 52,54 & 0,457 \\
\hline
\end{tabular}

${ }^{\star}$ Valores estatisticamente significantes $(p<0,05) ;{ }^{* *}$ Teste t de Student

Tabela 2. Comparação entre /// em onset e coda de sílaba nas provas de fonologia

\begin{tabular}{|c|c|c|c|c|c|}
\hline Grupo & Prova & Sílaba & Média - coda & Média - onset & Valor de $p$ \\
\hline \multirow[t]{3}{*}{ GI } & Fala espontânea & final & 0,86 & 48,78 & $<0,001^{\star}$ \\
\hline & Imitação & final & 0,00 & 21,95 & $<0,001^{*}$ \\
\hline & Nomeação & final & 0,00 & 32,67 & $<0,001^{*}$ \\
\hline \multirow[t]{4}{*}{ GII } & Fala espontânea & medial & 30,00 & 55,95 & 0,205 \\
\hline & & final & 7,50 & 41,16 & $0,001^{*}$ \\
\hline & Imitação & final & 8,89 & 33,33 & $0,001^{*}$ \\
\hline & Nomeação & final & 10,42 & 38,23 & $0,002^{*}$ \\
\hline
\end{tabular}

*Valores estatisticamente significantes $(p<0,05)$; ** Teste t de Student

não se adotou o /1/ como consoante de coda silábica. No que se refere à consoante final $/ \mathrm{N} /$, foi adotada nesta pesquisa a vertente dos estudos sobre este fonema levar à nasalização da vogal anterior ${ }^{(1)}$. Sendo assim, o /N/ também não foi considerado como coda silábica. Portanto, nesta posição, foram estudadas apenas as consoantes /R/ e /S/.

Para a análise dos dados foram considerados os acertos e erros, ou seja, as produções incorretas do fonema de acordo com o padrão do sistema fonológico do falante adulto do Português Brasileiro. Os erros consistiam de omissão do fonema, substituição por outro fonema e distorção acústica ou articulatória.

A análise estatística foi realizada por meio do teste $\mathrm{t}$ de Student com nível de significância de 0,05.

\section{RESULTADOS}

\section{Comparação entre /s/ em onset e coda silábica}

Na fala espontânea, houve comparação apenas em sílaba inicial nos dois grupos e em sílaba final no GII. Nota-se que a média de acerto das crianças no /s/ em onset de sílaba é maior comparada ao acerto em coda silábica, porém esta diferença não é significante (Tabela 1).

Na imitação, as crianças não apresentaram diferença estatística quanto ao /s/ em onset e coda de sílaba, com exceção do GII na sílaba final. Nesta, as crianças tiveram porcentagem de acerto estatisticamente mais baixa em onset que em coda silábica. Ressalta-se que no GI o /s/ em onset de sílaba também teve menos acertos que em coda de sílaba, mas a diferença não foi estatisticamente comprovada (Tabela 1).
Na nomeação, houve comparação apenas em sílaba inicial. Não houve diferença entre o /s/ em onset e coda de sílaba, embora no GI, as crianças tenham apresentado mais acerto no /s/ em coda que em onset silábico (Tabela 1).

\section{Comparação entre /r/ em onset e coda silábica}

Na fala espontânea (Tabela 2), a comparação entre o /r/ em onset e coda de sílaba, nos dois grupos, mostrou diferença significante entre as duas posições do fonema em sílaba final. Observa-se que em onset, houve mais acerto que em coda. No grupo de crianças mais velhas, também foi realizada comparação em sílaba medial. Porém, não houve diferença entre o /r/ em coda e onset de sílaba, apesar deste fonema ter tido mais acerto em onset.

Nas provas de imitação e nomeação (Tabela 2) foi realizada comparação apenas em sílaba final. Os dados constataram que o desempenho do fonema / $/$ / foi significantemente maior em onset que em coda silábica.

\section{DISCUSSÃO}

A hipótese do estudo era a de que haveria diferença intragrupo no acerto do fonema /s/ em posição de onset e de coda silábica e que, em relação ao / /, em onset e coda de sílaba, não haveria diferença.

Como pesquisas realizadas anteriormente mostraram que $\mathrm{o} / \mathrm{s} /$ em onset de sílaba é adquirido antes do arquifonema ${ }^{(8)}$, esperava-se que houvesse diferença entre estas duas posições. Porém, esta hipótese não foi confirmada. Nota-se que foi apre- 
sentada diferença apenas em sílaba final da imitação, mesmo assim, a coda teve mais acertos que o onset. Deve-se observar, porém, que muitos erros cometidos na produção dos grupos quanto ao /s/ em onset de sílaba foram distorções. Talvez, se elas fossem consideradas como acerto, houvesse diferença entre este fonema em onset e coda de sílaba. Já em coda, a maior parte dos erros foi de omissão de sílaba dentro da palavra e epêntese no final da palavra, mostrando que estes erros são mais graves e que comprometem a fonologia da língua, gerando, portanto, mais ininteligibilidade de fala.

As distorções são observadas durante a aquisição fonológica. Nesta pesquisa houve grande número de distorções tanto para /s/ como para / $/$ / o que corrobora achados de outras pesquisas $^{(8,16-17)}$. Estes erros tendem a diminuir com o avanço da idade.

Quanto à comparação do / / / em onset e coda, era esperado que não houvesse diferença entre estas posições, visto que em onset, este fonema é um dos últimos a ser adquirido na classe das líquidas ${ }^{(8)}$ assim como o arquifonema conforme citado em vários estudos ${ }^{(8,12)}$. Porém, a hipótese não foi confirmada. Houve diferença entre o fonema em onset e coda de sílaba, sendo que em onset, foi observado mais acertos. Esta diferença entre o fonema nas duas posições dentro da sílaba foi observada em um estudo anterior ${ }^{(25)}$.

Crianças com transtorno fonológico apresentam como processos mais ocorrentes a simplificação de líquida e a simplificação da consoante final ${ }^{(26-27)}$. Este dado encontrado sobre crianças em desenvolvimento fonológico típico ajuda no tratamento de crianças com transtorno fonológico visto que, em alguns estudos, opta-se por iniciar o trabalho terapêutico com sons mais complexos do sistema fonológico das crianças para que se atinja um efeito maior de generalização ${ }^{(28-30)}$. Com base nestes dados, seria importante iniciar o tratamento com o /r/ em coda de sílaba, para uma maior eficácia terapêutica.

\section{CONCLUSÃO}

De forma geral, notou-se que não houve diferença entre o /s/ em onset e coda silábica. Porém, quanto ao / $/$ /, houve diferença entre as duas posições na sílaba, sendo que em onset as crianças entre dois e três anos de idade tiveram mais acertos.

Estes dados são de grande importância na clínica fonoaudiológica não somente como um parâmetro sobre como estes fonemas se comportam durante o desenvolvimento típico auxiliando no diagnóstico, mas na decisão sobre a ordem em que estes fonemas devem ser trabalhados dentro da sílaba durante a intervenção com crianças com transtorno fonológico.

\section{AGRADECIMENTOS}

Ao Conselho Nacional de Desenvolvimento Científico e Tecnológico (CNPq) pela concessão de bolsa de doutorado da primeira autora, e à CAPES pela concessão de bolsa sanduíche da primeira autora.

\begin{abstract}
Purpose: To verify whether there is a difference between accuracy percentage of $/ \mathrm{s} /$ and $/ \mathrm{f} /$ in syllable onset and coda in children from 2:1 to 3:0 years old. Methods: Subjects of the research were 88 typically developing children: GI: 41 children from 2:1 to 2:6 years old, and GII: 47 children from 2:7 to 3:0 years old. All subjects attended public daycare centers; they did not have any complaints of language deficits or more than three episodes of otitis media, and were all Brazilian-Portuguese monolingual speakers. Data collection was carried out through three phonology tests: picture naming, imitation and spontaneous speech. Results: Regarding accuracy of the $/ \mathrm{s} /$, there was a difference between onset and coda in the final syllable of the naming test $(\mathrm{p}=0.038$ ), with better performance in coda than in onset, for GII. Although there was no statistical difference in the other tests and syllables analyzed, children from both groups presented better performance in onset than in coda, with exception of the GI in the final syllable of the imitation and in the initial syllable of the naming test. Considering accuracy of the /r/, in all comparisons of final syllable, children from both groups had statistically higher means in onset than in coda. In medial syllable, children showed better performance in onset, however, difference was not significant $(\mathrm{p}=0.205)$. Conclusion: In general, there was no difference between the $/ \mathrm{s} /$ in syllabic onset and coda. On the other hand, regarding the / $\mathrm{r} /$, there was a difference between the two positions within the syllable, and children from both groups showed more accuracy in the onset of the syllable.
\end{abstract}

Keywords: Child language; Child development; Language development; Speech articulation tests; Speech production measurement; Phonetics

\title{
REFERÊNCIAS
}

1. Câmara Júnior JM. Estrutura da língua portuguesa. 34a ed. Petrópolis: Vozes; 2001.

2. Silva TC. Fonética e fonologia do português: roteiro de estudos e guia de exercícios. 2a ed. São Paulo: Contexto; 1999.

3. Yavas M. Padrões de aquisição da fonologia do português. Letras de Hoje. 1988;23(2):7-30.
4. Wertzner HF, Galea DE, Almeida RC. Uso do processo fonológico de simplificação de velar em crianças de 2;1 a 3;0 anos de idade. J Bras Fonoaudiol. 2001;2(8):233-8.

5. Galea DE, Wertzner HF. Índices de fala em crianças em desenvolvimento fonológico típico, Pediatria (São Paulo). 2005;27(3):172-180. 
6. Wertzner HF, Carvalho IA. Ocorrências de "erros" nos fonemas fricativos durante o processo de aquisição do sistema fonológico. J Bras Fonoaudiol. 2000;2(2):67-74.

7. Olivera CC. Sobre a aquisição das fricativas. In: Lamprecht RR. Aquisição fonológica do português: perfil de desenvolvimento e subisídios para a terapia. Porto Alegre: Artmed; 2004. Capítulo 5.

8. Wertzner HF. Aquisição da articulação: um estudo em crianças de três a sete anos. Estudos de Psicologia. 1994;11(1/2):11-21.

9. Mezzomo CL. Sobre a aquisição da coda. In: Lamprecht RR. Aquisição fonológica do português: perfil de desenvolvimento e subisídios para a terapia. Porto Alegre: Artmed; 2004. Capítulo 8.

10. Hernandorena CL, Lamprecht RR. A aquisição das consoantes líquidas do português. Letras de Hoje. 1997;32(4):7-22.

11. Rigatti AP, Fonseca RP, Ramos AP. Aquisição normal e desviante do rótico alveolar simples em dois dialetos do português brasileiro. PróFono. 2001;13(2):157-64.

12. Mezzomo CL. A análise acústica como subsídio para a descrição da aquisição do constituinte coda. Letras de Hoje. 2003;38(2):75-82.

13. Galea DE; Wertzner HF. Phonological processes of syllabic structure in typical developing brazilian children. In: ASHA Convention; 2005; San Diego. Anais; 2005.

14. Wertzner HF, Galea DE. Análise da ocorrência de processos fonológicos em vocábulos inseridos em frases. J Bras Fonoaudiol. 2002;3(10):48-53.

15. Vitor RM, Cardoso-Martins C. Desenvolvimento fonológico de crianças pré-escolares da região noroeste de Belo Horizonte. Psicol Rev (Belo Horizonte). 2007;13(2):383-98.

16. Pereira MM, Bianchini EM, Carvalho GT, Jardim ZM. Investigação da ocorrência e caracterização de distorções do [s] em crianças de 3 a 10 anos. Rev Soc Bras Fonoaudiol. 2003;8(1):10-8.

17. Wertzner HF, Sotelo MB, Amaro L. Analysis of distortions in children with and without phonological disorders. Clinics. 2005;60(2):93-102.

18. Munson B. Variability in /s/ production in children and adults: evidence from dynamic measures of spectral mean. J Speech Lang Hear Res. 2004;47(1):58-69.

19. Vogel Sosa A, Stoel-Gammon C. Patterns of intra-word phonological variability during the second year of life. J Child Lang. 2006;33(1):3150 .
20. Tomé, MC; Farias. R; Araújo, SM; Schimitt, BE. Ceceio interdental e alterações oclusais em crianças de 03 a 06 anos. Pró-Fono. 2004;16(1):19-30.

21. Fonseca RA, Tucci TA, Rodriguez RC, Gomes IC, Bianchini EM. A correlação entre ceceio frontal e o crescimento infantil. Rev Soc Bras Fonoaudiol. 2005;10(4):211-7.

22. Befi-Lopes DM. Vocabulário. In: Andrade CR, Befi-Lopes DM, Fernandes FD, Wertzner HF. ABFW - Teste de linguagem infantil nas áreas de fonologia, vocabulário, fluência e pragmática. Carapicuíba: Pró-Fono; 2000. Capítulo 2.

23. Wertzner HF. Fonologia. In: Andrade CR, Befi-Lopes DM, Fernandes FD, Wertzner HF. ABFW - Teste de linguagem infantil nas áreas de fonologia, vocabulário, fluência e pragmática. Carapicuíba: Pró-Fono; 2000. Capítulo 1.

24. Shriberg LD, Kwiatkowski J. Continuous speech sampling for phonologic analysis of speech-delayed children. J Speech Hear Disord. 1985;50(4):323-34.

25. Wertzner HF. Articulação: aquisição do sistema fonológico dos três aos sete anos. [tese]. São Paulo: Universidade de São Paulo, Faculdade de Filosofia, Letras e Ciências Humanas; 1992.

26. Wertzner HF, Herrero SF, Pires SC, Ideriha PN. Classificação do distúrbio fonológico por meio de duas medidas de análise: porcentagem de consoantes corretas (PCC) e índice de ocorrência dos processos (PDI). Pró-Fono. 2001;13(1):90-7.

27. Wertzner HF, Papp AC, Galea DE. Provas de nomeação e Imitação como instrumentos de diagnóstico do transtorno fonológico. Pró-Fono. 2006;18(3):303-12.

28. Elbert M, Gieru J. Handbook of clinical phonology: approaches to assessment and treatment. 2a ed. Austin: Pro-ed; 1986.

29. Elbert M. Clinical forum: phonological assessment and treatment: consideration of error types: a response to Fey. Lang Speech Hear Serv Sch. 1992;23:241-6.

30. Barlow JA. Phonological change and the representation of consonant clusters in Spanish: a case study. Clin Linguist Phon. 2005;19(8):65979. 